\title{
Inflammatory response study of gellan gum impregnated duck's feet derived collagen sponges
}

\author{
Jeong Eun Songa, Seon Eui Lee ${ }^{a}$, Se Rom Cha ${ }^{a}$, Na Keum Jang ${ }^{a}$, Nirmalya Tripathy ${ }^{a}$, \\ Rui L. Reis ${ }^{\mathrm{b}}$ and Gilson Khang ${ }^{\mathrm{a}}$
}

aDepartment of BIN Fusion Technology, Department of Polymer Nano Science \& Technology and Polymer Fusion Research Center, Chonbuk National University, Jeonju, Republic of Korea; 'b3's Research Group Biomaterials, Biodegradables and Biomimetics, University of Minho, Headquarters of the European Institute of Excellence on Tissue Engineering and Regenerative Medicine, Guimaraes, Portugal

\begin{abstract}
Tissue engineered biomaterials have biodegradable and biocompatible properties. In this study, we have fabricated sponges using duck's feet derived collagen (DC) and gellan gum (GG), and further studied its inflammatory responses. The as-prepared duck's feet DC/GG sponges showed the possibility of application as a tissue engineering material through in vitro and in vivo experiments. The physical and chemical properties of sponges were characterized by compression strength, porosity, and scanning electron microscopy, etc. In vitro cell viability were investigated using 3-(4,5-dimethylthiazol2-yl)-2,5 diphenyltetrazolium bromide (MTT) assay. An inflammatory response was studied after seeding RAW264.7 cells on as-fabricated sponges using reverse transcriptase-polymerase chain reaction. In vivo studies were carried out by implanting in subcutaneous nude mouse followed by extraction, histological staining. Collectively, superior results were showed by DC/GG sponges than GG sponge in terms of physical property and cell proliferation and thus can be considered as a potential candidate for future tissue engineering applications.
\end{abstract}

\section{ARTICLE HISTORY}

Received 16 May 2016

Accepted 12 July 2016

\section{KEYWORDS}

Gellan gum; collagen; sponge; inflammatory responses; tissue regeneration

\section{Introduction}

In the field of tissue engineering, biomaterials play an important role via promoting cell adhesion, migration, and differentiation in the body.[1] Thus, they are fabricated in numerous forms such as films, sponges, and scaffolds and widely used to replace the damaged tissue or wounds. Ideally, materials employed in clinical studies should be biocompatible, biodegradable, $[2,3]$ since their interaction with the foreign bodies will tend to affect inflammation reactions in the body.[4,5] Inflammatory response, as the initial defense mechanism for transmitting a signal causes a specific immune response which prevents the spread of bacterial infection in the human body. However, it causes tissue damage and infectious diseases in excessive immune response.[6] Therefore, an inflammatory reaction must be 
considered while preparing the scaffolds. In this study, we have fabricated sponge with a biomaterial for application to tissue engineering such as bone, cartilage, etc.

Gellan gum (GG) is a linear and anionic polysaccharide with the repeating unit consisting of a-L-rhamnose, b-D-glucose, and b-D-glucuronate.[7-9] Also, GG is colorless and have heat, acid and enzyme resistance properties.[10,11] In particular, it is well known for its high permeability, ease in adjusting the physical properties (such as acidic or ionic), and nontoxic, which further makes it suitable for good interaction between the cells and the surrounding tissue. However, due to its low mechanical properties, it has been less exploited for the field of tissue engineering.[7] Collagen and fibrous protein consist of extracellular matrix (ECM), are present in a large amount in skin, bone, cartilage, teeth, muscles, etc. $[12,13]$ Collagen, when ingested as food improves immune function, promote regeneration action of the cell and make strong joints. They are also known to maintain the metabolism activation and moisturize the skin. It includes several factors for promoting interaction of the cell with its excellent biodegradability, as used in tissue engineering.[14-18] In our previous reports, duck's feet derived collagen (DC) has been reported as an effective antioxidant and anti-inflammatory material in comparison with cow or pig derived collagen. [19] Thus, herein, we have employed DC because of its higher type I collagen content and excellent anti-oxidant effect. As well, it is hypothesized that GG sponge impregnated with DC showing low antigenicity, will further promote cell renewal and improves the gellan gum and anti-inflammatory properties for tissue regeneration. Thus, the DC/GG sponge with good physical properties, enhanced cell proliferation and low inflammatory responses can be envisioned as a potential material for various applications in tissue engineering.

\section{Materials and methods}

\subsection{Materials}

Gellan gum (GG) (Gelzan ${ }^{\mathrm{Tm}}$, Sigma-Aldrich Co., U.S.A) with an average molecular weight of $1,000,000 \mathrm{~g} / \mathrm{mole}$ was purchased. Collagen was extracted from the duck's feet purchased in local market of Korea. All the reagents and organic solvents were used HPLC grade.

\subsection{Collagen extraction}

Duck' feet derived collagen (DC) was prepared according to our previous reported study. $[20,21]$ In brief, first, flippers were cut to $10 \mathrm{~mm}$ in size and washed with distilled water. Then, washed tissues were defatted with $0.5 \mathrm{M}$ sodium hydroxide solution for $24 \mathrm{~h}$, followed by washing with methanol and chloroform in a ratio of 3:1, and ethanol and subsequent acetone, respectively. After 5\% citric acid treatment, the supernatant was collected and centrifuged at 12,000 rpm for $15 \mathrm{~min}$; the supernatant was removed and the precipitate was again centrifuged with ethanol. Finally, the precipitated collagen was lyophilized. Lyophilized collagen was pulverized to fine powder using Freezing Mill (6700 SPEX Inc., U.S.A).

\subsection{Fabrication of gellan gum sponges}

Gellan gum (GG) sponges were prepared by lyophilization. Briefly, GG was prepared as 2\% $\mathrm{w} / \mathrm{v}$ solution and heated to $90^{\circ} \mathrm{C}$ at $200 \mathrm{rpm}$ for $30 \mathrm{~min}$. Thereafter, the temperature was 
decreased to $60{ }^{\circ} \mathrm{C}$ and removed $10 \%$ v/v GG solution and phosphate buffer saline (PBS, pH 7.4; Sigma-Aldrich Co., U.S.A) solution of the same amount was added. Then, the solutions were kept at $50^{\circ} \mathrm{C}$ for 30 min under constant stirring. GG solution was poured onto 48 -well plate $\left(1 \mathrm{~mL} /\right.$ well); refrigerated at $4{ }^{\circ} \mathrm{C}$ for $4 \mathrm{~h}$; and frozen at $-20{ }^{\circ} \mathrm{C}$ for $4 \mathrm{~h}$ and $-75^{\circ} \mathrm{C}$ for $24 \mathrm{~h}$. The frozen gels were lyophilized for $48 \mathrm{~h}$. In this process, the gelation mechanism occurs after the coil to helix transition. [7,22] The GG sponges may be physically cross-linked due to temperature variation.

For fabrication of collagen solution penetrated into GG sponges (DC/GG), GG sponges were immersed in $1 \mathrm{wt} \%$ collagen solution (containing $0.5 \mathrm{M}$ acetic acid and collagen powder) for $4 \mathrm{~h}$ and lyophilized. These fully dried sponges $(5 \mathrm{~mm}$ in height and $8 \mathrm{~mm}$ in diameter) were stored in a desiccator under vacuum until use.

\subsection{Sponges characterization}

Morphology and pore size of GG and DC/GG sponges were observed by scanning electron microscopy (SEM, Hitachi, S-3000, Japan), the porosity in the sponges was measured as a percentage using the following equation.[23]

$$
\text { Porosity }(\%)=\frac{V_{1}-V_{3}}{V_{2}-V_{3}} \times 100
$$

where $V_{1}$ : the initial volume of distilled water, $V_{2}$ : the volume of distilled water-impregnated sponge, $V_{3}$ : the distilled water-impregnated scaffolds were then removed and the residual distilled water volume.

Compressive strength of each sponge was also measured using TMS-Pro instrument (Food Technology Corporation, Sterling, VA, U.S.A). In order to calculate the strength and height of scaffolds, the samples were moved down at a target distance to specimen of $2.5 \mathrm{~mm}$ with a speed of $1 \mathrm{~mm} / \mathrm{s}$ and force of $0.2 \mathrm{~N}$. Measurements were performed on 5 samples for GG and DC/GG sponges and results were expressed as the mean \pm standard deviation.

\subsection{Antioxidant ability}

Antioxidant activities of sponges were measured using DPPH (1,1-diphenyl-2-picrylhydrazly) free radical scavenging. A $20 \mathrm{mg} / \mathrm{mL}$ sponges (sample) and $0.1 \mathrm{mg} / \mathrm{mL}$ ascorbic acid (control) were added to $1 \mathrm{~mL}$ of $0.2 \mathrm{mM} \mathrm{DPPH}$ in methanol. The reaction mixture was shaken and aged for $30 \mathrm{~min}$ at room temperature under dark conditions. $100 \mu \mathrm{L}$ of the solubilized solution was then plated on 96-well plates and the intensity of absorption was examined using Synergy ${ }^{\mathrm{Mx}}$ monochromator-based multi-mode microplate reader (Biotek instruments, Inc., U.S.A) at $517 \mathrm{~nm}$. The methanol solution of DPPH was used as blank. The DPPH radical scavenging activity was calculated using the following equation.

$$
\text { Savenging effect }(\%)=\left[1-\frac{(A-B)}{C}\right] \times 100
$$

where A: absorbance of sample, B: absorbance of blank, and C: absorbance of control. 


\subsection{Cell culture}

NIH/3T3 fibroblasts (NIH/3T3 mouse embryo fibroblast, KCLB21658) and RAW 264.7 (Mouse leukaemicte monocy macrophage cell line, KCLB40071) were obtained from the Korean Cell Line Bank (KCLB). NIH/3T3 fibroblasts were cultured in RPMI1640 (Roswell park memorial institute medium) containing $10 \%(\mathrm{v} / \mathrm{v})$ fetal bovine serum (FBS, Gibco), and $1 \%$ antibiotics (100 units $/ \mathrm{mL}$ penicillin and $100 \mathrm{mg} / \mathrm{mL}$ streptomycin (Invitrogen). RAW 264.7 cells were cultured in the Dulbecco's modified Eagle's medium (DMEM, high glucose, Gibco) containing 10\% (v/v) fetal bovine serum (FBS, Gibco), and 1\% antibiotics (100 units/ $\mathrm{mL}$ penicillin and $100 \mathrm{mg} / \mathrm{mL}$ streptomycin (Invitrogen). All cultures were maintained in $5 \% \mathrm{CO}_{2}$ incubator at $37^{\circ} \mathrm{C}$ with the medium changed every other day.

\subsection{Cell adhesion and morphology analysis}

To observe the cell adhesion and morphology of NIH/3T3 fibroblasts on sponges, $10 \mu \mathrm{L}$ of cell suspension was seeded in GG and DC/GG sponges having cell density of $1 \times 10^{5}$ cells/ well and cultured for 1-3 weeks in vitro. Before cell seeding, all sponges were sterilized in $70 \%$ ethyl alcohol for 30 min followed by rinsing it 3 times in PBS solution for 5 min every time. The samples were stabilized with $2.5 \% \mathrm{v} / \mathrm{v}$ glutaraldehyde (Sigma-Aldrich) in distilled water at $4{ }^{\circ} \mathrm{C}$ for $24 \mathrm{~h}$ and then sponges were subjected to sequential dehydration for $30 \mathrm{~min}$ each with ethanol series $(50,60,70,80,90$, and 100\%). Adhered cells and scaffolds were overlaid with white gold of $200 \mu \mathrm{m}$ in thickness using a plasma sputter (Emscope SC500 K, $\mathrm{UK}$ ) under argon gas. The morphologies of cells on the sponges were examined by Bio-LV SEM (SN-3000 Hitachi, Japan).

\subsection{Cell proliferation study}

To observe the cell proliferation, NIH/3T3 fibroblasts were seeded individually at a density of $1 \times 10^{5}$ cells in GG and DC/GG sponges. Cell viability was measured using 3-(4,5-dimethylthiazole-2-yl)-2,5-diphenyltetrazolium-bromide (MTT, sigma-aldrich) assay at 1-3 days in vitro. All constructs were transferred into 24-well plates followed by addition of $100 \mu \mathrm{L}$ of MTT solution ( $5 \mathrm{mg} / \mathrm{mL}$ stock in PBS, Sigma-Aldrich) and incubated for $4 \mathrm{~h}$ at $37^{\circ} \mathrm{C}$ at each experimental time point. The solution was then replaced with $1 \mathrm{~mL}$ dimethylsulfoxide (DMSO, Sigma-Aldrich) to dissolve formazan crystals. Of the solubilized solution, $100 \mu \mathrm{L}$ solution was plated in 96-well plates. The absorbance was taken at $570 \mathrm{~nm}$ using Synergy Mx monochromator-based multi-mode microplate reader (Biotek instruments, Inc., U.S.A).

\section{9. $R T-P C R$ analysis}

To evaluate the level of inflammatory reactions and analyze the mRNA expression, reverse transcriptase-polymerase chain reaction (RT-PCR) was performed. RAW 264.7 cells were seeded on the GG, DC/GG sponges in 24-well plates and cultured for 1-3 days. Total RNA was extracted from the sponges using $1 \mathrm{~mL}$ of trizol (Invitrogen ${ }^{\mathrm{Tm}}$ ) and $0.2 \mathrm{~mL}$ of chloroform. The supernatants were then transferred to a new tube and precipitated with $0.5 \mathrm{~mL}$ of isopropanol (Sigma-Aldrich) and $5 \mu \mathrm{L}$ of polyacryl carrier (Molecules Research Center, Inc., Cincinnati, OH, U.S.A). The RNA samples were reverse transcribed into cDNA using 
Oligo $(\mathrm{dT})$ primer $\left(\right.$ Invitrogen $\left.^{\mathrm{TM}}\right), 5 \times$ first strand buffer $\left(\right.$ Invitrogen $\left.^{\mathrm{TM}}\right)$, dNTP $(\mathrm{dGTP}, \mathrm{dATP}$, dTTP, dCTP, Gibco), RNase inhibitor (Invitrogen $^{\mathrm{TM}}$ ), SuperScript II (Invitrogen ${ }^{\mathrm{Tm}}$ ), RNase H reverse transcriptase (Invitrogen ${ }^{\mathrm{TM}}$ ), and DNase/RNase free water (Gibco) using the Takara Thermal cycler (Takara Bio Inc, Japan).

Each primers ( $\beta$-actin, TNF- $\alpha$, COX-2 and IL-6) were extended using a PCR Master kit (Roche, Germany), including 2 units of Taq DNA polymerase. All PCR products were separated via electrophoresis on $1.2 \%(\mathrm{w} / \mathrm{v})$ agarose gel containing ethidium bromide (SigmaAldrich) and visualized under UV light (Vilber Lourmat ETX-20.M, France) at $300 \mathrm{~nm}$. The mRNA expressions of TNF- $\alpha$, COX-2 and IL- 6 were normalized to the housekeeping gene, $\beta$-actin.

\subsection{Histological and immunohistochemical evaluation}

For histological and immunohistochemical evaluation, GG and DC/GG sponges implanted into the subcutaneous armpit of four weeks old wister rats (100-150 g, female, Orient Animal Co., Korea). Wister rats were anesthetized with intramuscular injection with $150 \mu \mathrm{L}$ of Zoletil (Virbac S. A, FRA) and Domitor (Orion Pharma, FIN) by ratio of 2:1. The hairs on rat's back were removed using an electric shaver. The surgical site was washed with povidone-iodone. GG and DC/GG sponges (5 $\mathrm{mm}$ in height and $8 \mathrm{~mm}$ in diameter) sterilized with $70 \%$ of ethanol were implanted into the subcutaneous dorsum of rats. Then the implants were harvested after 1 and 4 weeks. All experiment procedures were performed with the approval of the Chonbuk National University Animal Care Committee, Jeonju, Korea (CBNU 2016-50). The extracted sponges were fixed in 10\% formalin (Sigma-Aldrich), dehydrated with a series of graded ethanol, and embedded in paraffin. The paraffin blocks were sectioned to $6 \mu \mathrm{m}$ thickness and then stained with hematoxylin and eosin (H\&E), ED-1, according to the manufacturer's introduction. Each stained samples were examined for cell distribution, morphology, and sGAG production.

\subsection{Statistical analysis}

Statistical analyses were carried out using the student's t-test. Differences were considered significant where ${ }^{*} p<0.05,{ }^{* *} p<0.005$, and ${ }^{* *} p<0.001$.

\section{Results and discussion}

\subsection{Physical properties of sponges}

Figure 1 shows the SEM images of gellan gum sponge (GG) and impregnated gellan gum sponge in collagen solution (DC/GG). The porous surface of as-prepared GG sponges demonstrates smooth surfaces. In contrast, DC/GG sponges displayed a change in the surface morphology after the impregnation of DC collagen on the surface of GG sponges. The surfaces of DC/GG sponge appear to be rougher compared to GG sponge. Table 1 shows the pore size, porosity, and compressive strength of the sponges. The average pore sizes were $299.6 \pm 67.37$ and $114 \pm 29.24 \mu \mathrm{m}$ for GG and DC/GG sponges, respectively. This can be explained by the decreased pore size of DC/GG sponge owing to the impregnated DC in GG sponge during the manufacturing process of the sponges. These results also 

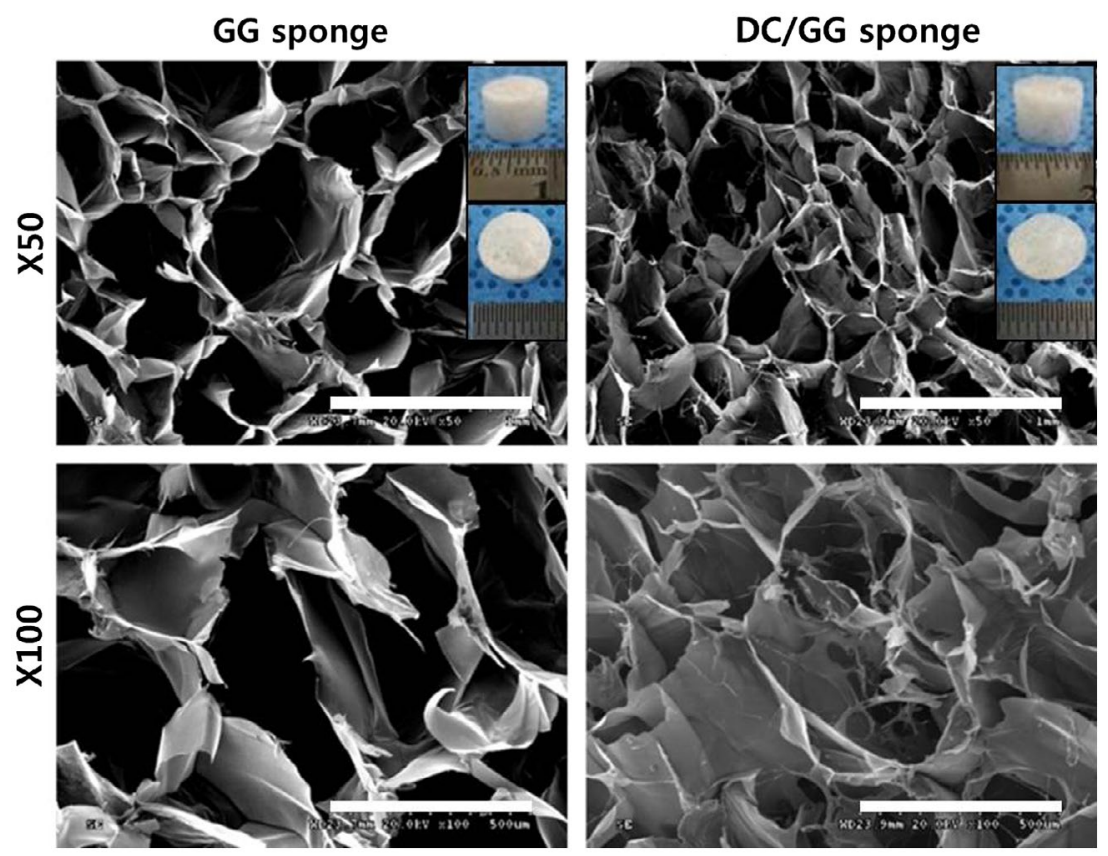

Figure 1. SEM microphotographs of gellan gum sponge (GG) and impregnated gellan gum sponge in collagen solution (DC/GG) (magnification with $50 \times$ and $100 \times$, scale bar $=1 \mathrm{~mm}$ and $500 \mu \mathrm{m}$ ).

Table 1. Assays of pore size $(\mu \mathrm{m})$, porosity $(\%)$, and compression of modulus $(\mathrm{kPa})$.

\begin{tabular}{lcc}
\hline Assays & GG sponge & DC/GG sponge \\
\hline Pore size $(\mu \mathrm{m})$ & $299.6 \pm 67.37$ & $114.42 \pm 29.24$ \\
Porosity $(\%)$ & $91.6 \pm 3.14$ & $87.8 \pm 1.61$ \\
Compression of modulus $(\mathrm{kPa})$ & $9.7 \pm 1.47$ & $11.3 \pm 1.26$ \\
\hline
\end{tabular}

present a consistency with the SEM results. According to the porosity results, GG and DC/ GG sponges showed $91.6 \pm 3.14$ and $87.8 \pm 1.61 \%$, respectively. The mechanical properties of the sponges were studied by measuring compression strength of sponges. The samples showed $9.7 \pm 1.47 \mathrm{kPa}$ for GG sponges and $11.3 \pm 1.26 \mathrm{kPa}$ for DC/GG sponges. The DC coating was found to improve the compressive strength of the DC/GG sponges as compared to GG sponge.

\subsection{Antioxidant ability}

DPPH (1,1-diphenyl-2-picrylhydrazyl) free radical method is an antioxidant assay based on electron transfer that produces a violet solution in ethanol. This free radical is reduced in the presence of an antioxidant molecule, changing the yellow color with reduced DPPH. $[24,25]$ The scavenging activity of the GG and DC/GG sponges were found as $51.8 \pm 3.92$ and $64.5 \pm 4.71 \%$, respectively (shown in Figure 2). Based on these results, it can be concluded that DC/GG sponge was 1.25 times more active than GG sponge, which can be ascribed to the impregnated DC. Collagen can inhibit the oxidation of lipids in vivo and is also known 


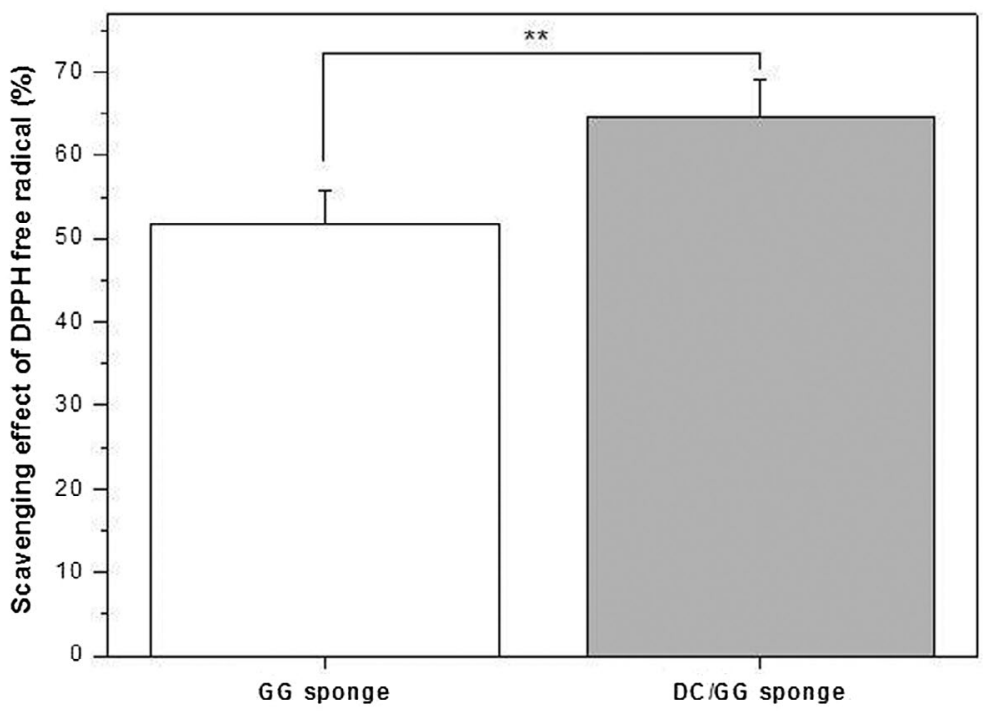

Figure 2. Antioxidant ability of sponges on DPPH free radical $\left({ }^{* *} p<0.05\right)$.

to help the structure and form of cells. The DC/GG sponges showed higher scavenging activity than GG sponges.

\subsection{Cell adhesion and proliferation}

Figure 3 displays the SEM images of NIH/3T3 fibroblasts after 1-3 days of culture with the as-fabricated sponges. At 1st day, the morphological appearances of GG sponge seeded with NIH/3T3 fibroblasts revealed a round shaped cells and grown in confluence on the DC/GG sponge surface. This result can be confirmed over time clearly. Also, cells and their ECM were obviously seen at any culture time. In particular, after 3 days of culture, cells on surface of DC/GG sponge were found to form a uniform monolayer than GG sponge surface. The collagen penetrated in the pores of GG sponge surface becomes rough surface, which promotes better cell attachment and proliferation. Also, ECM of collagen provides a favorable environment for cell adhesion.[26]

Figure 4 shows the NIH/3T3 fibroblasts cells proliferation on the GG and DC/GG sponges after 1-3 days of culturing, studied by MTT assay. The MTT results observed after 1-3 days of NIH/3T3 fibroblasts cells seeding on the GG sponges was $1.08 \pm 0.0216$, $1.09 \pm 0.0484$, and $1.17 \pm 0.0752$, respectively. For the DC/GG sponges, the values were obtained as $1.15 \pm 0.066,1.22 \pm 0.0494,1.38 \pm 0.0424$, respectively. Overall, all the groups showed increased cells proliferation from 1 to 3 days, however the DC/GG sponges showed more increased cell proliferation compared to GG sponges at all times point. As previously mentioned, DC is attached to GG sponge surface that provided growth environment for cell proliferation and adhesion. Accordingly, cell proliferation was higher in DC/GG sponge than GG sponge. These results also present a consistency with SEM results. 

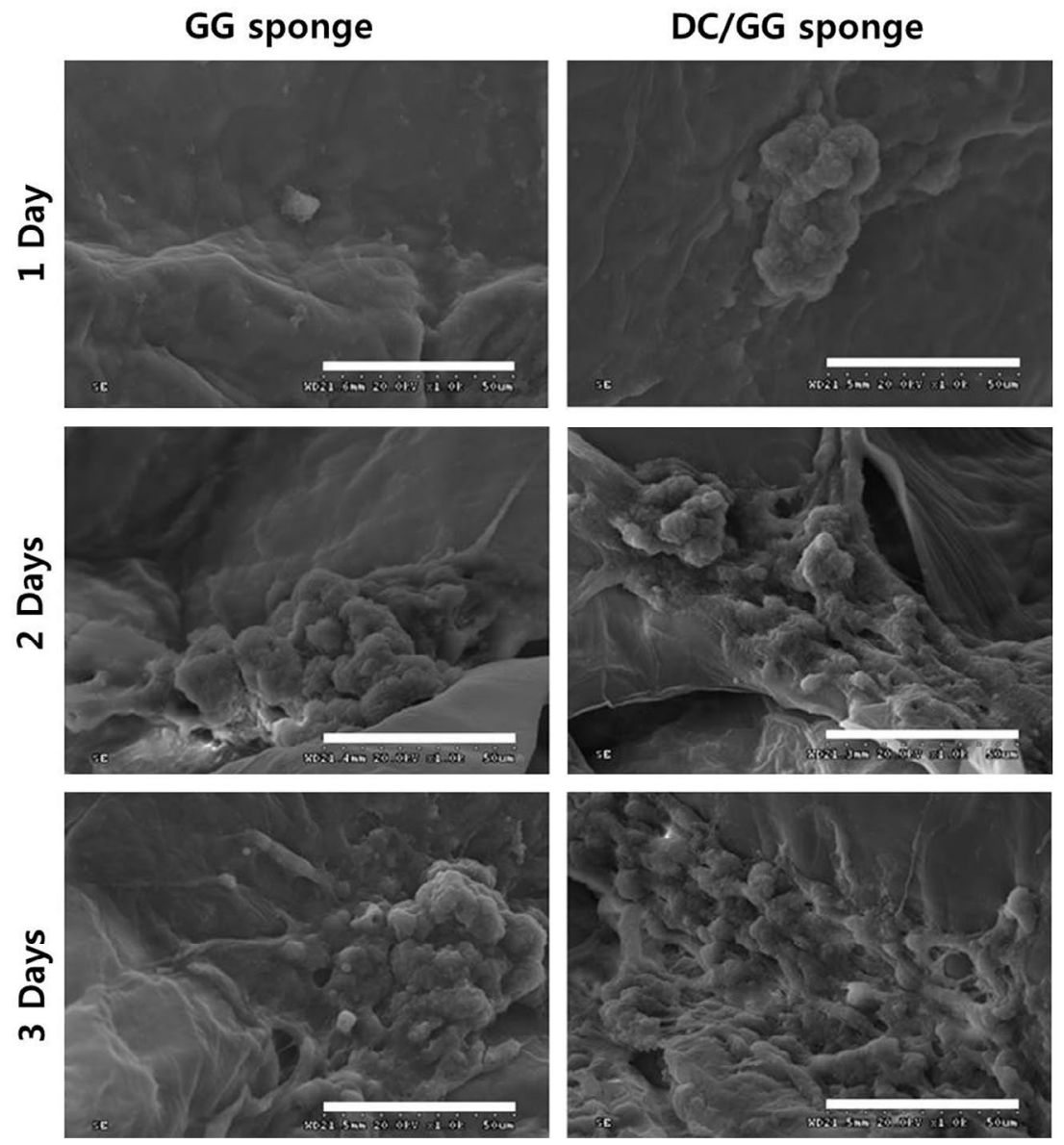

Figure 3. SEM microphotographs of NIH/3T3 cell morphology on GG and DC/GG sponges after 1-3 days (magnification with $1000 \times$, and scale bar $=50 \mu \mathrm{m}$ ).

\subsection{Gene expression analysis}

Figure 5 shows the degree of gene expression of $\beta$-actin, Tumor necrosis factor-alpha (TNF- $\alpha$ Interleukin-1 $\beta$ (IL-1 $\beta$ ) and COX-2 analyzed by RT-PCR on 1-3 days of RAW 264.7 culture in vitro. TNF- $\alpha$ is well-known cytokine involved in systemic inflammation and is one of the cytokines that make up the acute phase reaction. IL- $1 \beta$ is an important mediator of the inflammatory response and is involved in a variety of cellular activities. It is produced chiefly by activated macrophages. COX-2 is selectively induced by pro-inflammatory cytokines at the site of inflammation. In all groups, $\beta$-actin as housekeeping gene was well-expressed.

Although the expression of TNF- $\alpha$, IL-1 $\beta$, COX-2 increased in DC/GG sponges than GG sponges at 1st day, however the expression of TNF- $\alpha$, IL-1 $\beta$, COX-2 decreased in DC/ GG sponges than GG sponge on 2 nd and 3rd day of culture. Inflammatory response was confirmed to decrease in GG and DC/GG sponges with increase in time. 


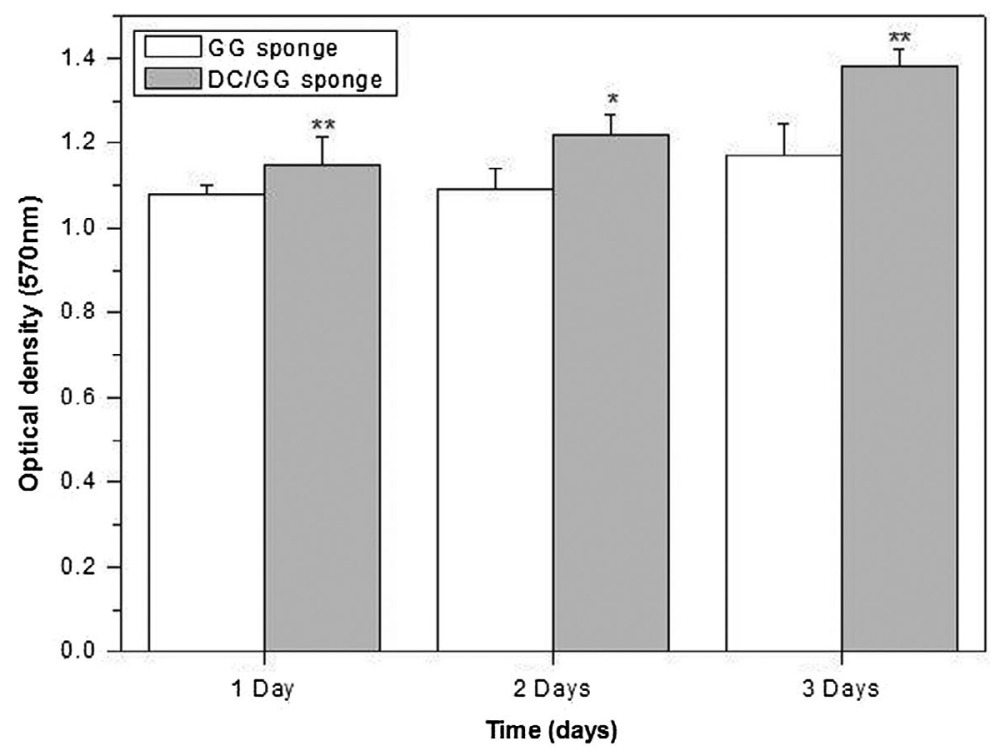

Figure 4. Cell viability of NIH/3T3 cells in GG and DC/GG sponges was analyzed by MTT assay after 1-3 days post-seeding in vitro $\left({ }^{*} p<0.5\right.$ and $\left.{ }^{* *} p<0.05\right)$.

(A)

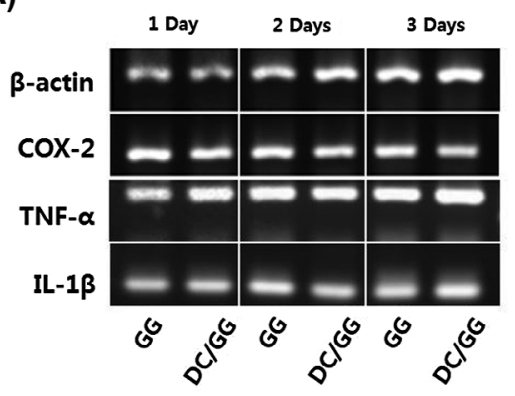

(C)

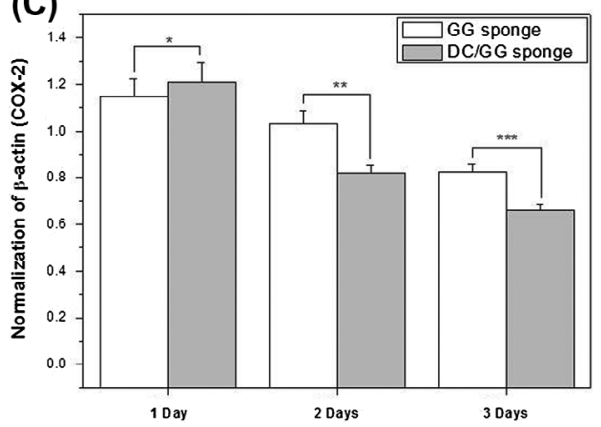

(B)

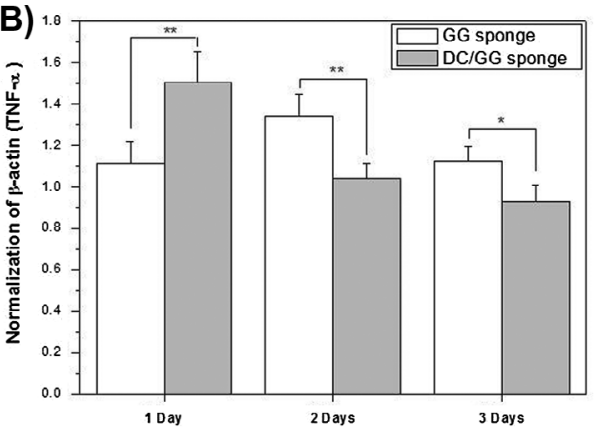

(D)

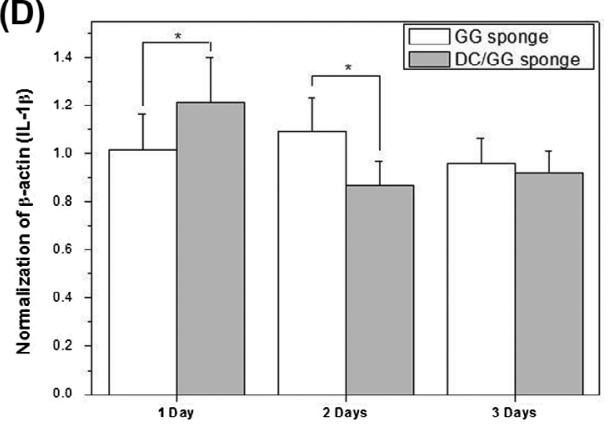

Figure 5. (a) Gene expression of TNF- $\alpha$, COX-2 and IL-1 $\beta$ analyzed by RT-PCR on 1-3 days. Agarose gel electrophoresis normalization of TNF- $\alpha$ (b) COX-2 (c) and IL- $1 \beta$ (d) by $\beta$-actin $\left({ }^{*} p<0.01,{ }^{* *} p<0.05\right.$, and $\left.{ }^{* * *} p<0.01\right)$. 


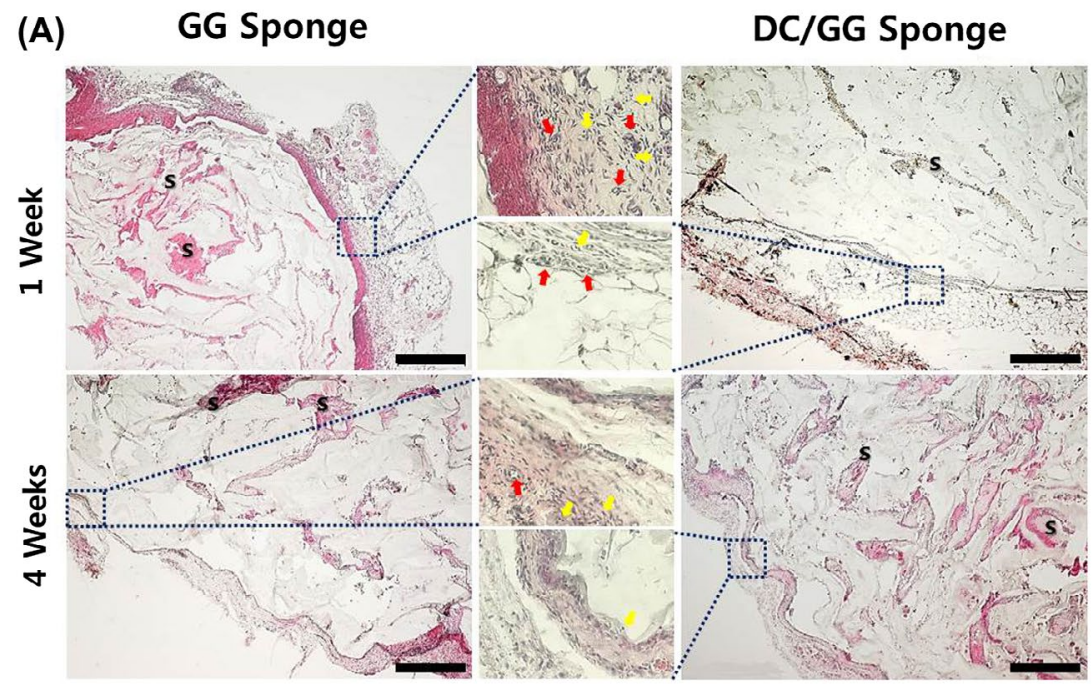

(B) GG Sponge DC/GG Sponge

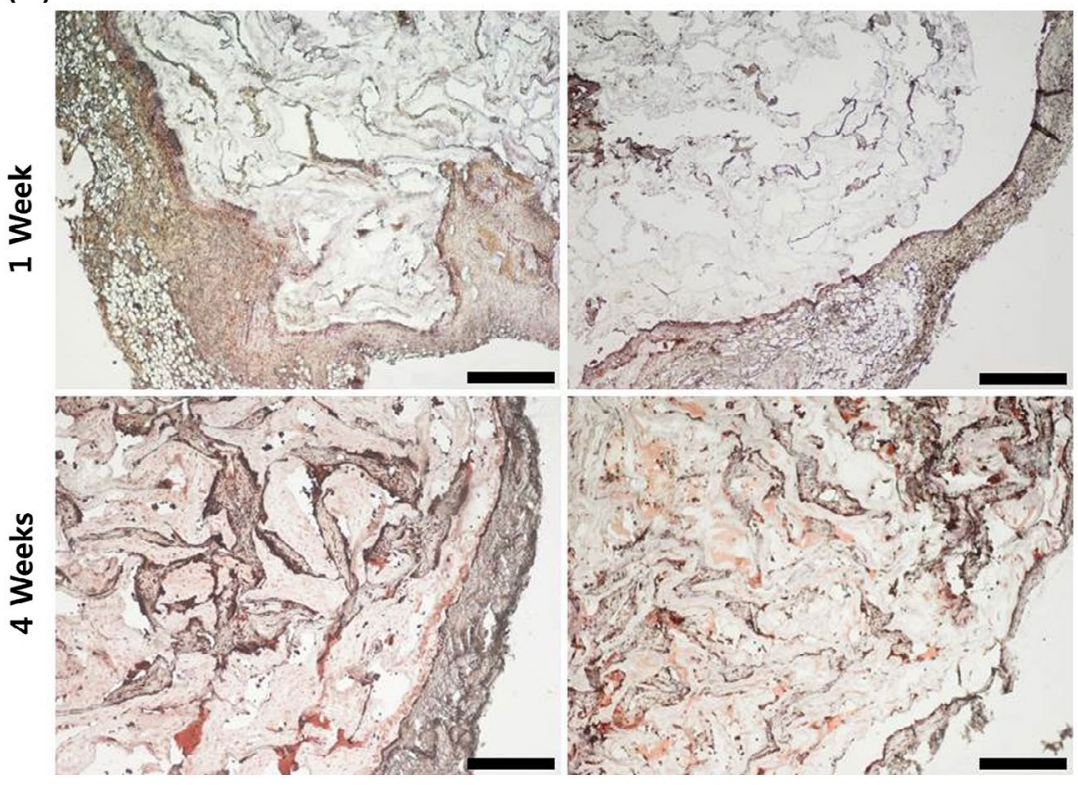

Figure 6. (A) H\&E, (B) ED-1 stained histological section of tissue at sponges after 1 and 4 weeks of implantation. S: sponge, red arrows: foreign body gainat cells, yellow arrows: macrophages (magnification with $40 \times$, scale bar $=500 \mu \mathrm{m}$ ). (Please see the online article for the colour version of this figure: http:// dx.doi.org/10.1080/09205063.2016.1213218.)

\subsection{Histological and immunohistochemical evaluation}

As shown in Figure 6, histological and immunohistochemical evaluation were performed to observe the interaction and inflammatory response between the sponge and tissue at 1 st and 4th week of implantation in vivo using $\mathrm{H} \& \mathrm{E}$ and $\mathrm{ED}-1$ staining. $\mathrm{H} \& \mathrm{E}$ staining is a counter stain that is a component of cytoplasm in acidophilc ingredient stained by eosin and nucleus in baseophilc ingredient stained by hemalum in neutrophil leukocyte. Neutrophil leukocyte, if the tissue is damaged appears first, it will rapidly undergo apoptosis at site of 
inflammation. Therefore, inflammation is reduced with the passage of time by phagocytosis of neutrophil and macrophage.

In Figure 6(A) shows the presence of large amount of macrophages and multinucleated giant cells in the GG and DC/GG sponge surface at one week of implantation. In particular, compared to DC/GG sponges, the GG sponges showed the formation of dense infiltrated thick cell wall. However, inflammatory cells and the thickness of fiber wall were significantly reduced at 4 weeks with an increase in time in all the groups. In addition, active formation of cytoplasm was seen in case of DC/GG sponge than GG sponge because DC has affected the tissue regeneration. Figure 6(B) shows the result of immunohistochemical staining using the macrophage marker CD-68. Initially at 1 st week, an increased numbers of ED-1 positive cells from the surrounding tissue were observed for the GG sponge than DC/GG sponge. At 4th week, the numbers of ED-1 positive cells were remarkably reduced for the GG sponge than DC/GG sponge, presenting a consistency with the H\&E staining results. In other words, the thickness of GG sponges wall was more than that of DC/GG sponges at 1 st and 4 th weeks. The reason is because the DC has the low antigenicity. Therefore, it can be concluded that DC/GG sponge is a potential material for tissue engineering owing to the inclusion of DC in the sponges with low inflammatory responses.

\section{Conclusions}

We have fabricated GG and DC/GG sponges to evaluate its efficiency as potential scaffold for tissue engineering applications. The DC/GG sponges displayed an increased mechanical strength owing to more compact, dense pores and high compressive strength as compared to the GG sponges. The DC/GG sponges also demonstrated improved cell viability and proliferation rate, since the presence of DC in the sponges have significantly reduced the expression of inflammatory cytokines, identified by $\mathrm{H} \& \mathrm{E}$ and ED-1 staining. In particular, the DC/GG sponges significantly decrease infiltration of inflammatory cells around the sponge as time passes at post-transplant. Thus, the DC/GG sponge with good physical properties, enhanced cell proliferation and low inflammatory responses can be envisioned as a potential material for future tissue engineering applications.

\section{Disclosure statement}

No potential conflict of interest was reported by the authors.

\section{Funding}

This work was supported by Technology Commercialization Support Program [grant number 81400503-2-HD020], Ministry for Food, Agriculture, Forestry and Fisheries (MIFAFF) and grant of the Korea Health Technology R\&D Project through the KHIDI [grant number HI15C2996], Ministry of Health and Welfare (MOHW), Republic of Korea.

\section{References}

[1] Chen FM, Liu X. Advancing biomaterials of human origin for tissue engineering. Prog. Polym. Sci. 2016;53:86-168.

[2] Lu Q, Wang X, Lu S, et al. Nanofibrous architecture of silk fibroin scaffolds prepared with a mild self-assembly process. Biomaterials. 2011;32:1059-1067. 
[3] Kanimozhi K, Khaleel Basha S, Sugantha Kumari V. Processing and characterization of chitosan/PVA and methylcellulose porous scaffolds for tissue engineering. Mater. Sci. Eng., C. 2016;61:484-491.

[4] Aamodt JM, Grainger DW. Extracellular matrix-based biomaterial scaffolds and the host response. Biomaterials. 2016;86:68-82.

[5] Przekora A, Ginalska G. In vitro evaluation of the risk of inflammatory response after chitosan/ HA and chitosan/ $\beta$-1,3-glucan/HA bone scaffold implantation. Mater. Sci. Eng., C. 2016;61:355361.

[6] Almeida CR, Serra T, Oliveira MI, et al. Impact of 3-D printed PLA- and chitosan-based scaffolds on human monocyte/macrophage responses: unraveling the effect of 3-D structures on inflammation. Acta Biomater. 2014;10:613-622.

[7] Gantar A, da Silva LP, Oliveira JM, et al. Nanoparticulate bioactive-glass-reinforced gellan-gum hydrogels for bone-tissue engineering. Mater. Sci. Eng., C. 2014;43:27-36.

[8] Salunke SR, Patil SB. Ion activated in situ gel of gellan gum containing salbutamol sulphate for nasal administration. Int. J. Biol. Macromol. 2016;87:41-47.

[9] Khang G, Lee SK, Kim HN, et al. Biological evaluation of intervertebral disc cells in different formulations of gellan gum-based hydrogels. J. Tissue Eng. Regen. Med. 2015;9:265-275.

[10] Osmałek T, Froelich A, Tasarek S. Application of gellan gum in pharmacy and medicine. Int. J. Pharm. 2014;466:328-340.

[11] Lozano R, Stevens L, Thompson BC, et al. 3D printing of layered brain-like structures using peptide modified gellan gum substrates. Biomaterials. 2015;67:264-273.

[12] Kim SH, Park HS, Lee OJ, et al. Fabrication of duck's feet collagen-silk hybrid biomaterial for tissue engineering. Int. J. Biol. Macromol. 2016;85:442-450.

[13] Mahmoud AA, Salama AH. Norfloxacin-loaded collagen/chitosan scaffolds for skin reconstruction: preparation, evaluation and in-vivo wound healing assessment. Eur. J. Pharm. Sci. 2016;83:155-165.

[14] Cholas R, Kunjalukkal Padmanabhan S, Gervaso F, et al. Scaffolds for bone regeneration made of hydroxyapatite microspheres in a collagen matrix. Mater. Sci. Eng., C. 2016;63:499-505.

[15] Ghazanfari S, Khademhosseini A, Smit TH. Mechanisms of lamellar collagen formation in connective tissues. Biomaterials. 2016;97:74-84.

[16] Chen J, Li L, Yi R, et al. Extraction and characterization of acid-soluble collagen from scales and skin of tilapia (Oreochromis niloticus). LWT-Food Sci. Technol. 2016;66:453-459.

[17] Chandika P, Ko SC, Oh GW, et al. Fish collagen/alginate/chitooligosaccharides integrated scaffold for skin tissue regeneration application. Int. J. Biol. Macromol. 2015;81:504-513.

[18] Fauzi M, Lokanathan Y, Aminuddin B, et al. Ovine tendon collagen: extraction, characterisation and fabrication of thin films for tissue engineering applications. Mater. Sci. Eng., C. 2016;68:163171.

[19] Cha SR, Jeong HK, Kim SY, et al. Effect of duck's feet derived collagen sponge on skin regeneration: in vitro study. Polymer Korea. 2015;39:493-498.

[20] Kuk H, Kim HM, Kim SM, et al. Osteogenic effect of hybrid scaffolds composed of duck feet collagen and PLGA. Polymer-Korea. 2015;39:846-851.

[21] Kim SM, Kim HM, Kuk H, et al. Characterization and effect of inflammatory reaction of duck-feet derived collagen/poly(lactic-co-glycolide)(PLGA) hybrid scaffold. Polymer-Korea. 2015;39:837-845.

[22] Moxon SR, Smith AM. Controlling the rheology of gellan gum hydrogels in cell culture conditions. Int. J. Biol. Macromol. 2016;84:79-86.

[23] Ju HW, Lee OJ, Lee JM, et al. Wound healing effect of electrospun silk fibroin nanomatrix in burn-model. Int. J. Biol. Macromol. 2016;85:29-39.

[24] Garcia EJ, Oldoni TL, Alencar SM, et al. Antioxidant activity by DPPH assay of potential solutions to be applied on bleached teeth. Braz. Dent. J. 2012;23:22-27.

[25] Lupascu FG, Dash M, Samal SK, et al. Development, optimization and biological evaluation of chitosan scaffold formulations of new xanthine derivatives for treatment of type-2 diabetes mellitus. Eur. J. Pharm. Sci. 2015;77:122-134.

[26] Wang J, Yang Q, Cheng N, et al. Collagen/silk fibroin composite scaffold incorporated with PLGA microsphere for cartilage repair. Mater. Sci. Eng., C. 2016;61:705-711. 